\title{
BMJ
}

\section{Effect of unsupervised home based proprioceptive training on recurrences of ankle sprain: randomised controlled trial}

\author{
Maarten D W Hupperets, PhD student, ${ }^{1}$ Evert A L M Verhagen, senior researcher, ${ }^{1,2}$ Willem van Mechelen, \\ professor $^{1,2}$
}

Department of Public and Occupational Health, EMGO Institute for Health and Care Research, VU University Medical Centre, Van der Boechorststraat 7 , 1081 BT, Amsterdam, Netherlands

${ }^{2}$ Body@Work Research Centre for Physical Activity, Work and Health, TNO VUmc, Amsterdam, Netherlands

Correspondence to: $\mathrm{W}$ van

Mechelen

w.vanmechelen@vumc.n

Cite this as: $B M J$ 2009;339:b2684 doi:10.1136/bmj.b2684

\section{ABSTRACT}

Objective To evaluate the effectiveness of an unsupervised proprioceptive training programme on recurrences of ankle sprain after usual care in athletes who had sustained an acute sports related injury to the lateral ankle ligament.

Design Randomised controlled trial, with one year followup.

Setting Primary care.

Participants 522 athletes, aged 12-70, who had sustained a lateral ankle sprain up to two months before inclusion; 256 (120 female and 136 male) in the intervention group; 266 (128 female and 138 male) in the control group.

Intervention Both groups received treatment according to usual care. Athletes allocated to the intervention group additionally received an eight week home based proprioceptive training programme.

Main outcome measure Self reported recurrence of ankle sprain.

Results During the one year follow-up, 145 athletes reported a recurrent ankle sprain: $56(22 \%)$ in the intervention group and 89 (33\%) in the control group. Nine athletes needed to be treated to prevent one recurrence (number needed to treat). The intervention programme was associated with a $35 \%$ reduction in risk of recurrence. Cox regression analysis showed significantly fewer recurrent ankle sprains in the intervention than in the control group. This effect was found for self reported recurrent ankle sprains (relative risk $0.63,95 \%$ confidence interval 0.45 to 0.88 ), recurrent ankle sprains leading to loss of sports time $(0.53,0.32$ to $0.88)$, and recurrent ankle sprains resulting in healthcare costs or lost productivity costs $(0.25,0.12$ to 0.50$)$. No significant differences were found between medically treated athletes in the intervention group and medically treated controls. Athletes in the intervention group who were not medically treated had a significantly lower risk of recurrence than controls who were not medically treated. Conclusions The use of a proprioceptive training programme after usual care of an ankle sprain is effective for the prevention of self reported recurrences. This proprioceptive training was specifically beneficial in athletes whose original sprain was not medically treated. Trial registration ISTRCN34177180

\section{INTRODUCTION}

Regular participation in physical activity and sports is beneficial for health. ${ }^{1}$ There is also an increased risk of injury, however, of which ankle sprains are the most common in many sports. ${ }^{2}$

Each day an estimated 23000 ankle sprains occur in the United States, equalling about one sprain per 10000 people per day. ${ }^{3}$ The most recent count of sports injuries in the Netherlands (2002-3) estimated an annual total of 1300000 acute sports injuries, of which 234000 were ankle sprains. ${ }^{4}$ Of these, 110000 (47\%) required some form of medical treatment. Recent research showed that, in the Netherlands, the mean total cost (direct and indirect) of one ankle sprain was about $€ 360$ (£308; \$507), ${ }^{5}$ giving an estimated annual cost of $€ 84240000$ in the Netherlands alone. In addition, there is strong evidence that in the year after injury, athletes have twice the risk of a recurrent ankle sprain..$^{6-9} \mathrm{Up}$ to half of these recurrences result in chronic pain or instability, ${ }^{10}$ potentially leading to disability and prolonged medical care. The high rate of ankle sprains across all sports, as well as the severity and subsequent negative consequences on future participation, motivates preventive measures.

A preventive effect of various measures has been found only for athletes with previous ankle sprains. ${ }^{11-15}$ A primary preventive effect of tape, braces, or proprioceptive training has yet to be established. The dynamic recursive model of sports injury ${ }^{16}$ creates insight in the aetiology of ankle sprain recurrences. After an index ankle sprain, the athlete's intrinsic risk factors are altered, ${ }^{17-24}$ resulting in an increased predisposition to re-injury. ${ }^{16}$

Although treatment of ankle sprain aims at recovery, it does not seem to lower the increased risk of re-injury. This hypothesis is substantiated by secondary analyses of a preventive trial in top level volleyball athletes. ${ }^{25}$ After the introduction of a proprioceptive training programme ankle sprain recurrences were reduced by $50 \%$, and over $90 \%$ of the previously injured athletes completed a full rehabilitation programme for their index ankle sprain.

This finding added to the already available literature warrants the prolongation of usual care with additional preventive efforts to effectively prevent recurrences of 
ankle sprain. We evaluated the effectiveness of an individual home based proprioceptive training programme after rehabilitation and treatment by usual care to prevent ankle sprain recurrences.

\section{METHODS}

The randomised controlled trial had a follow-up of one year, chosen because the increased risk for ankle sprain recurrences seems to exist only during the first year after injury. ${ }^{6-9}$ Athletes were randomised to intervention or control, with stratification for sex, type of enrolment, and usual care of ankle sprain. A statistician who had no knowledge regarding any other characteristics of the participants performed the randomisation.

Athletes were recruited from August 2006 to August 2007 through medical channels (11 emergency rooms, five general practices, and four physical therapy offices) throughout the Netherlands and non-medical channels (through adverts in newspapers, sports magazines, sports tournaments, and on the internet). All were active sports participants aged 12-70 who had sustained an ankle sprain in the preceding two months.

Before inclusion, a physical therapist contacted each injured athlete by phone and conducted a thorough oral assessment of the reported ankle sprain using an injury registration questionnaire, derived from a previously used injury registration form. ${ }^{12}$ This included questions on diagnosis, cause, and aetiology of the injury. If the injury had been medically treated, the advised treatment and the exact profession of the person who treated the injury were recorded with the diagnosis provided.

All participants received treatment according to usual care, defined as any form of rehabilitative treatment used by the athlete, without interference from the authors. Athletes allocated to the intervention group were informed that they would receive an eight week proprioceptive training programme, preferably starting immediately after inclusion but not before the end of rehabilitation with usual care and re-participation in sports.

\section{Operational definitions}

\section{Treatment}

Non-medical: no medical care giver

Medical: medical care giver

Paramedical: physical therapist, exercise therapist, or manual therapist

Intramural: general surgeon, orthopaedic surgeon

Extramural: general practitioner, centre for sports medicine

\section{Ankle sprain recurrence}

Self reported: sudden inversion of the same ankle

Time loss: sudden inversion of the same ankle causing athlete to stop current (sports) activity or miss (part of) the next planned sports activity, or both

Leading to costs: sudden inversion of the same ankle resulting in healthcare costs or work absence, or both

\section{Return to participation}

Athlete completed cost diaries until she or he was able to participate fully in her or his primary sports

\section{Intervention}

The programme was derived from a previously described programme, ${ }^{12}$ modified by two physical therapists to consist of more general exercises that were to be carried out individually. Feasibility was tested in a pilot study. A detailed description of the different basic exercises of the proprioceptive training programme is described elsewhere, ${ }^{26}$ and the training programme is in the appendix on bmj.com. The programme prescribed three training sessions a week, with a maximum duration of 30 minutes a session. Athletes were encouraged to perform the exercises as part of their normal warm up. Exercises gradually increased in difficulty and training load during the eight week programme.

Athletes in the intervention group received a balance board (Avanco AB, Sweden), exercise sheets, and an instructional DVD showing all exercises of the programme. All information was also provided on a website, accessible only for those in the intervention group.

\section{Outcome measures}

The outcome was the incidence density of ankle sprain and its 95\% confidence interval, expressed as incident ankle sprains per 1000 hours of exposure. We differentiated self reported sudden inversions of the same ankle according to severity ${ }^{27}$ : recurrences leading to loss of sports time and recurrences resulting in healthcare costs or lost productivity costs, or both.

\section{Exposure and injury registration}

During the one year follow-up, athletes reported recurrences and details of their sports participation for each training session and match on a monthly basis. Athletes who reported a recurrence completed a web based questionnaire similar to the injury registration form that was completed orally before inclusion. Athletes who had sustained a recurrence also received a cost diary that registered all healthcare costs and costs due to loss of productivity from the moment of injury until full recovery.

Athletes in the intervention group self rated compliance after four weeks and eight weeks of training. To rule out spill over or contamination between groups, every month we asked those in the control group whether they had participated in proprioceptive training during the past month.

On the basis of the completed injury registration forms, a physical therapist and the primary researcher, who were blinded to group allocation, independently rated all registered ankle injuries as acute lateral ankle sprains or other ankle injuries. There was agreement on all independently assessed injury registrations. The box gives the definitions used to register ankle sprain recurrences. A similar method of injury registration and diagnosis was used previously in other studies. $^{1228}$ 
Table 1| Characteristics of athletes according to allocated group. Figures are numbers (percentages) of participants unless stated otherwise

\begin{tabular}{lcc} 
& Intervention (n=256) & Control (n=266) \\
No of females & 120 & 128 \\
\hline Mean (SD) age (years) & $28.6(11.8)$ & $28.0(11.6)$ \\
\hline Mean (SD) weight (kg) & $73.4(13.3)$ & $71.7(13.0)$ \\
\hline Mean (SD) height (cm) & $176.9(9.9)$ & $177.4(9.5)$ \\
\hline Mean (SD) experience (years) & $10.82(8.8)$ & $10.75(8.0)$ \\
\hline Mean (SD) sports exposure (hours) & $117.73(93.59)$ & $115.35(113.51)$ \\
\hline Usual care: & $171(49)$ & $86(50)$ \\
\hline Medical & $85(50)$ & $124(47)$ \\
\hline Non-medical & $120(47)$ & $62(23)$ \\
\hline History of ankle sprain: & $54(21)$ & $80(30)$ \\
\hline Index & $82(32)$ & $62(23.0)$ \\
\hline Last recurrence $<12$ months ago & & $64(23.8)$ \\
\hline Last recurrence $>12$ months ago & $47(18.1)$ & \\
\hline Ankle protective devices: & $73(28.2)$ & \\
\hline Brace & & \\
\hline Tape & & \\
\hline
\end{tabular}

\section{Sample size}

We considered a difference of $50 \%$ in the incidence of recurrent ankle sprains between the groups after one year to be clinically relevant. ${ }^{12}$ With a prevalence of recurrent ankle sprain of $13 \%$ in one year, ${ }^{9}$ we needed 275 people per group to detect the intended difference of $50 \%$ in the incidence of recurrences, with a power of $80 \%$ and an $\alpha$ of $5 \%$. Assuming a dropout rate of about $20 \%$, we needed 688 athletes to detect a potentially clinically relevant effect.

\section{Statistical methods}

All statistical analyses were undertaken according to a pre-specified plan. Injury incidences and corresponding 95\% confidence intervals were calculated for total sports participation as the number of recurrent ankle sprains reported per 1000 hours of sports, with exposure time of each individual player until the first recurrent ankle sprain. We also carried out a subgroup analysis on medical care for the inclusion ankle sprain.

Cox regression analysis compared risk of recurrence of ankle sprain between the groups, with adjustment for age, type of sport (contact or non-contact), and level of sports (competitive or recreational). Other variables were checked for confounding or interaction, but none was found. All analyses were carried out according to the intention to treat principle. Differences were considered significant at $\mathrm{P}<0.05$.

Compliance numbers were presented as the absolute number of athletes (and percentages) in each category. Athletes in the control group who performed some form of proprioceptive training during followup were presented as a total number and a percentage of the total number of athletes in that group.

\section{RESULTS}

We recruited 522 athletes, 351 (67\%) through medical channels and 171 (33\%) through non-medical channels. Stratification ensured equal numbers for key factors in the intervention $(\mathrm{n}=256)$ and control group $(\mathrm{n}=266)$, and at baseline there were no significant differences between groups (table 1). The figure shows the flow of participants through the study. The dropout rate was similar between groups. Five out of 266 athletes in the control group $(2 \%)$ reported performing some sort of proprioceptive training exercises during follow-up.

\section{Exposure and injury characteristics}

Participants took part in 30140 hours of sports in the intervention group and 30682 hours in the control group. During the one year follow-up, 145 (28\%) athletes reported a recurrent ankle sprain: $56 / 256(22 \%)$ in the intervention group and 89/266 (33\%) in the control group.

The overall incidence of ankle sprain per 1000 hours of sports was 1.86 (95\% confidence interval 1.37 to 2.34 ) in the intervention group and 2.90 (2.30 to 3.50) in the control group (table 2).

\section{Effect of proprioceptive training programme}

Cox regression analysis showed that the risk of self reported recurrences of ankle sprain was significantly lower in the intervention group than in the control group (relative risk $0.63,95 \%$ confidence interval 0.45 to 0.88 , table 2 ). Similarly, significantly lower relative risks were found for the intervention athletes for time loss $(0.53,0.32$ to 0.88$)$ and costs $(0.25,0.12$ to $0.50)$. Our results show that nine athletes need to be treated to prevent one ankle sprain recurrence. Furthermore, the programme led to a $35 \%$ relative risk reduction in the intervention group.

\section{Effect on medically treated athletes}

Cox regression subgroup analysis was carried out for ankle sprains that included medical treatment during usual care at time of inclusion. Within this subgroup, we found an intervention effect only for recurrences leading to costs $(0.24,0.08$ to 0.72$)$ (table 3$)$. We found no differences for self reported recurrences $(0.89,0.54$ to 1.45$)$ and recurrences leading to loss of sports time $(0.62,0.30$ to 1.30$)$.

\section{Effect on non-medically treated athletes}

Cox regression analysis showed that the intervention group athletes who reported non-medical treatment of their ankle sprain had a significantly lower risk of recurrence than controls. This effect was found for self reported recurrences $(0.45,0.28$ to 0.72$)$, for recurrences leading to loss of sports time $(0.47,0.23$ to 0.96$)$, and for recurrences leading to costs $(0.25,0.10$ to 0.61$)$.

\section{Compliance with the programme}

A total of $58(23 \%)$ athletes in the intervention group said they had fully complied with the eight week proprioceptive training programme; $75(29 \%)$ said they had been partially compliant; 89 (35\%) were classified as not compliant. Compliance with the training programme was unknown for $34(13 \%)$ athletes as they 


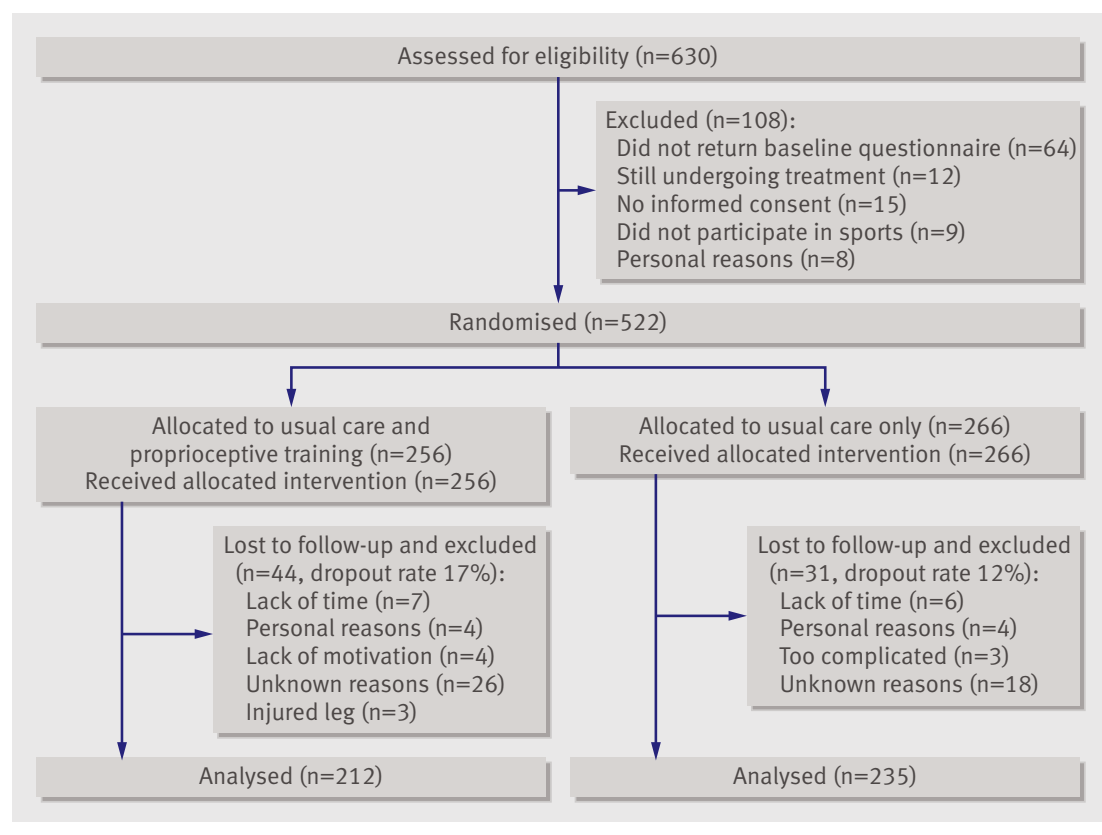

Flowchart of athletes through trial

did not complete the questionnaires. Five out of 266 in the control group (2\%) said they had performed some sort of proprioceptive training exercises during the one year follow-up. These athletes performed proprioceptive training exercises as part of medical treatment of a recurrence of ankle sprain and were not incorporated in the analysis.

\section{DISCUSSION}

An unsupervised home based proprioceptive training programme given in addition to usual care is effective in reducing the incidence of recurrent ankle sprains in athletes. In line with our hypothesis, we found a twofold reduction in risk of recurrence for self reported recurrences. We found the same effect for time loss because of recurrences. Other proprioceptive training trials have recently shown a reduction in the incidence of ankle sprain recurrence. ${ }^{12}{ }^{13}$ Ankle sprains leading to costs were 3.6 times higher in control athletes than in intervention athletes. There are no comparative data available for recurrences leading to costs.

\section{Study limitations}

We used self reports for recording the initial ankle sprain, for which athletes were included in the study, and for recurrent ankle sprains during the study. As recurrences were reported on a monthly basis, recall bias was not likely. Misclassification of injuries (such

Table 2 | Incidence of injury (95\% confidence interval) per 1000 hours of participation in sports and relative risk (RR) by injury severity variables and allocated group

\begin{tabular}{llcc} 
Ankle sprain & \multicolumn{1}{c}{ Intervention } & Control & \multicolumn{1}{c}{ RR* $^{*}$} \\
Self reported & $1.86(1.37$ to 2.34$)$ & $2.90(2.30$ to 3.50$)$ & $0.63(0.45$ to 0.88$)$ \\
\hline Time loss & $0.65(0.38$ to 0.92$)$ & $1.17(0.82$ to 1.52$)$ & $0.53(0.32$ to 0.88$)$ \\
\hline Leading to costs & $0.29(0.11$ to 0.47$)$ & $1.08(0.74$ to 1.42$)$ & $0.25(0.12$ to 0.50$)$ \\
\hline
\end{tabular}

*Derived from Cox regression adjusted for age, type of sport, and level of sports. as a faulty diagnosis of acute lateral ankle ligament sprains) sustained during the follow-up, however, was possible. To minimise classification errors, we adapted registration forms from those used recently in a randomised trial in which self report was used for the registration of ankle injuries. ${ }^{12}$ All recorded injuries to the ankle were blinded for group assignment and independently diagnosed by two sports physicians as being acute lateral ankle ligament sprains or other ankle injuries. Both physicians agreed on all injuries. Furthermore, the method of registering injuries by self report was similar to that used in a recent cluster randomised controlled trial on the prevention of injuries in young female footballers. ${ }^{28}$

All self reported recurrent ankle sprains were registered as re-injuries. Although these sprains were mostly described as being mild and leading to short term discomfort, they could be classified as subjective sensations of giving way. ${ }^{29}$ These sensations are well known to occur in individuals with functional ankle instability.

Loss to follow-up, at $14 \%$, was considerably lower than the expected $20 \%$. Baseline variables of athletes that were lost to follow-up did not differ significantly from the other athletes. Therefore, we believe that bias because of selective dropout was limited.

\section{Relation to other studies}

To date, only one randomised controlled trial has studied the effect of a rehabilitative training programme on risk of recurrence of ankle sprain after an acute ankle ligament sprain. ${ }^{18}$ A year after injury, that study found a significant difference in re-injuries in favour of the intervention group. ${ }^{18}$ The study sample size, however, was low compared with that in our study (92 $v$ 522 ), considerably more athletes were lost to followup $(27 \% v 14 \%)$, and information on re-injuries was collected retrospectively a year after the acute ankle sprain. Whereas exercises in the trial by Holme et al. were supervised by physical therapists, ${ }^{18}$ we used an unsupervised training programme.

\section{Data validation}

We recruited athletes from all ages, all levels of sports, different types of treatment, and from large geographical regions of the Netherlands, so the external validity was high. Furthermore, as we found no differences between groups at baseline, in dropout rates, and in exposure during the study, the internal validity was also high. By using standard injury registration forms that were judged by two researchers independently, we assume that reliability and validity were ensured given our experience in a previous comparable study. Thus reliability for comparing the data between the intervention and the control groups was ensured.

\section{Compliance}

Although we found a significant reduction in the risk of ankle sprain recurrence, a higher compliance to the training programme could have resulted in more 
Table 3 | Incidence of injury ( $95 \%$ confidence interval) and relative risk (RR) by injury severity perspective and allocated group

\begin{tabular}{llll}
$\begin{array}{l}\text { Ankle sprain } \\
\text { Self reported: }\end{array}$ & \multicolumn{1}{c}{ Intervention } & \multicolumn{1}{c}{ Rontrol } \\
\hline Medical treatment & $2.02(1.28$ to 2.75$)$ & $2.12(1.42$ to 2.83$)$ & $0.89(0.54$ to 1.45$)$ \\
\hline Non-medical treatment & $1.71(1.07$ to 2.36$)$ & $3.79(2.78$ to 4.80$)$ & $0.45(0.28$ to 0.72$)$ \\
\hline Time loss: & & & \\
\hline Medical treatment & $0.65(0.26$ to 1.03$)$ & $1.13(0.66$ to 1.60$)$ & $0.62(0.30$ to 1.30$)$ \\
\hline Non-medical treatment & $0.65(0.27$ to 1.03$)$ & $1.22(0.70$ to 1.75$)$ & $0.47(0.23$ to 0.96$)$ \\
\hline Leading to costs: & & & \\
\hline Medical treatment & $0.23(0.00$ to 0.46$)$ & $1.18(0.69$ to 1.67$)$ & $0.24(0.08$ to 0.72$)$ \\
\hline Non-medical treatment & $0.35(0.07$ to 0.62$)$ & $0.97(0.51$ to 1.43$)$ & $0.25(0.10$ to 0.61$)$ \\
\hline
\end{tabular}

${ }^{*}$ Derived from Cox regression adjusted for age, type of sport, and level of sports.

pronounced differences between the groups. Compliance with the training programme was measured with a monthly compliance questionnaire. As direct contact with the individual athlete was impossible, this was the only option of monitoring compliance.

At least six weeks of proprioceptive training seem necessary to reduce the risk of re-injury, ${ }^{18}$ so partial compliance with the present training programme was probably insufficient to induce preventive effects.

\section{Generalisability}

As the intervention was implemented for both sexes, all ages, all types of sports, and at different levels of sports, the results indicate that the entire range of athletes, from young elite to intermediate and recreational senior athletes, would benefit from using the presented training programme for the prevention of recurrences of ankle sprain. By including non-medically treated and medically treated athletes, we covered a broad spectrum of injury severity. This suggests that the present training programme can be implemented in the treatment of all athletes. Furthermore, as it is reasonable to assume that ankle sprains not related to sports are comparable with those in sports, the programme could benefit the general population.

\section{Implications for medical care givers}

Medical care givers rely heavily on evidence based practice, using best research evidence available. The Cochrane Collaboration aims to improve healthcare

\section{WHAT IS ALREADY KNOWN ON THIS TOPIC}

Ankle sprains are the most common injuries in various sports

Proprioceptive training reduces recurrences in ankle sprain by $50 \%$

Despite treatment of an ankle sprain, risk of recurrence remains high

\section{WHAT THIS STUDY ADDS}

An unsupervised home based proprioceptive training programme prevents self reported recurrences of ankle sprain in acutely injured athletes

Nine people need to be treated to prevent one recurrence

Proprioceptive training is a useful addition to usual care, specifically in athletes who did not have medical treatment for their ankle sprain decision making through systematic reviews of the effects of healthcare interventions, which can be seen as the highest level of evidence. A Cochrane review on interventions for preventing ankle ligament injuries found limited evidence for the reduction in ankle sprain recurrences after ankle disc training exercises. ${ }^{30}$ Since the publication of the Cochrane review, however, several randomised controlled trials on proprioceptive training, apart from our study, have shown effectiveness in preventing recurrences of ankle sprain. ${ }^{121331}$ An updated Cochrane review could lead to new insights on how to treat ankle sprains, which could be useful for medical care givers around the world.

Contributors: MDWH participated in formulating the study hypothesis, registered, analysed, and interpreted the data, discussed core ideas and participated in writing the paper. EALMV initiated and coordinated the formulation of the study hypothesis, registered, analysed, and interpreted the data, discussed core ideas and participated in writing the paper. WvM discussed core ideas, contributed to writing the paper, and is guarantor.

Funding: This study was supported by a grant from the Netherlands Organization for Health Research and Development (ZonMw), grant number 750-20-002. No author or related institution has received any financial benefit from research in this study.

Competing interests: None declared.

Ethical approval: The study was approved by the medical ethics committee of the VU University Medical Center, Amsterdam,

Netherlands. All athletes gave individual informed consent. Additional parental informed consent was given for athletes under the age of 18 .

1 Haskell WL, Lee I, Pate RR, Powell KE, Blair SN, Franklin BA, et al. Physical activity and public health: updated recommendation for adults from the American College of Sports Medicine and the American Heart Association. Circulation 2007;116:1081-93.

2 Fong DT, Hong Y, Chan LK, Yung PS, Chan KM. A systematic review on ankle injury and ankle sprain in sports. Sports Med 2007;37:73-94.

3 Kannus P, Renstrom P. Treatment for acute tears of the lateral ligaments of the ankle. Operation, cast, or early mobilization. J Bone Joint Surg Am 1991;73:305-12.

4 Vriend I, Kampen LTB van, Schmikli S, Eckhardt J, Schoots W, den Hertog PC. Ongevalsletsels en sportblessures in kaart gebracht. Ongevallen en Bewegen in Nederland, 2002-2003. Amsterdam: Consument en Veiligheid, 2005.

5 Verhagen EALM, Van Tulder M, Van $\operatorname{der}$ Beek AJ, Bouter L, Van Mechelen W. An economical evaluation of a proprioceptive balance board training program for the prevention of ankle sprains in volleyball. Br J Sports Med 2005;39:111-5.

6 Bahr R, Bahr IA. Incidence of acute volleyball injuries: a prospective cohort study of injury mechanisms and risk factors. Scand J Med Sci Sports 1997;7:166-71.

7 Ekstrand J, Tropp H. The incidence of ankle sprains in soccer. Foot Ankle 1990;11:41-4.

8 Milgrom C, Shlamkovitch N, Finestone A, Eldad A, Laor A, Danon YL, et al. Risk factors for lateral ankle sprains: a prospective study among military recruits. Foot Ankle 1991;12:26-30.

9 Verhagen EALM, Van der Beek AJ, Bouter LM, Bahr RM, Van Mechelen W. A one-season prospective cohort study of volleyball injuries. Br J Sports Med 2004;38:477-81.

10 Sander E. Ligamentous injuries to the ankle. Am Fam Phys 1980;22:132-8.

11 Parkkari J, Kujala M, Kannus P. Is it possible to prevent sports injuries? Review of controlled clinical trials and recommendations for future work. Sports Med 2001;31:985-95.

12 Verhagen EALM, Van der Beek AJ, Twisk JWR, Bouter L, Bahr R, van Mechelen W. The effect of a proprioceptive balance board training program for the prevention of ankle sprains: a prospective controlled trial. Am J Sports Med 2004;32:1385-93.

13 Wedderkopp N, Kaltoft M, Holm R, Froberg K. Comparison of two intervention programmes in young female players in European handball; with and without ankle disc. Scand J Med Sci Sports 2003;13:371-5.

14 Tropp H, Askling C, Gillquist J. Prevention of ankle sprains. Am J Sports Med 1985;13:259-62. 
15 Surve I, Schwellnus MP, Noakes T, Lombard C. A fivefold reduction in the incidence of recurrent ankle sprains in soccer players using the Sport-Stirrup orthosis. Am / Sports Med 1994;22:601-6.

16 Meeuwisse WH, Tyreman H, Hagel B, Emery C. A dynamic model of etiology in sport injury: the recursive nature of risk and causation. Clin J Sport Med 2007;17:215-9.

17 Høiness P, Glott T, Ingjer F. High-intensity training with a bidirectional bicycle pedal improves performance in mechanically unstable ankles-a prospective randomized study of 19 subjects. Scand J Med Sci Sports 2003;13:266-71.

18 Holme E, Magnusson SP, Becher K, Bieler T, Aagaard P, Kjaer M. The effect of supervised rehabilitation on strength, postural sway, position sense and re-injury risk after acute ankle ligament sprain. Scand J Med Sci Sports 1999;9:104-9.

19 Kaminski TW, Perrin DH, Gansneder BM. Eversion strength analysis of uninjured and functionally unstable ankles. J Athl Train 1999;34:239-45.

20 Kaminski TW, Buckley BD, Powers ME, Hubbard T, Ortiz C, Mattacola C. Effect of strength and proprioceptive training on eversion and inversion strength ratios in subjects with unilateral functional ankle instability. Br J Sports Med 2003;37:410-5.

21 Sekir U, Yildiz Y, Hazneci B, Ors F, Aydin T. Effects of isokinetic training on strength, functionality and proprioception in athletes with functional ankle instability. Knee Surg Sports Traumatol Arthroscop 2007;15:654-64.

22 Willems T, Witvrouw E, Verstuyft J, Vaes P, De Clerq D. Proprioception and muscle strength in subjects with a history of ankle sprains and chronic instability. J Athl Train 2002;37:487-93.
23 Bernier JN, Perrin DH. Effect of coordination training on proprioception of the functionally unstable ankle. J Orthop Sports Phys Ther 1998;27:264-75.

24 Eils E, Rosenbaum D. A multi-station proprioceptive exercise program in patients with ankle instability. Med Sci Sports Exerc 2001;33:1991-8.

25 Verhagen EALM. Ankle sprains in volleyball. Players off balance? [Thesis.] Amsterdam, Netherlands: VU Medical Center, 2004.

26 Hupperets MDW, Verhagen EALM, Mechelen W van. The 2BFit study: is an unsupenised proprioceptive balance board training programme, given in addition to usual care, effective in preventing ankle sprain recurrences? Design of a randomized controlled trial. BMC Musc Dis 2008;9:71.

27 Van Mechelen W. The severity of sports injuries. Sports Med 1997;24:176-80.

28 Soligard T, Myklebust G, Steffen K, Holme I, Silvers H, Bizzini M, et al. Comprehensive warm-up programme to prevent injuries in young female footballers: cluster randomised controlled trial. BMJ 2008;337:a2469.

29 Freeman MAR. Instability to the foot after injuries to the lateral ligament of the ankle. J Bone Joint Surg Br 1965;47:669-77.

30 Handoll HH, Rowe BH, Quinn KM, de Bie R. Interventions for preventing ankle ligament injuries. Cochrane Database Syst Rev 2001;3:CD000018.

31 Emery CA, Cassidy JD, Klassen TP, Rosychuck RJ, Rowe BH. Effectiveness of a home-based balance-training program in reducing sports-related injuries among healthy adolescents: a cluster randomized controlled trial. CMA/ 2005;172:749-54.

Accepted: 26 February 2009 